\title{
Antibacterial activity of grapefruit peel extracts and green-synthesized silver nanoparticles
}

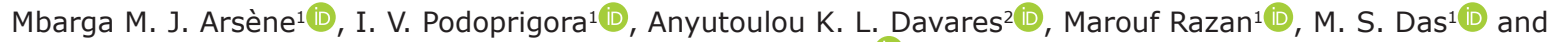 \\ A. N. Senyagin ${ }^{1}$ (D)
}

1. Department of Microbiology and Virology, Institute of Medicine, RUDN University, Moscow, Russia; 2. Department of Food Sciences and Nutrition, National School of Agro-industrial Sciences, University Ngaoundere, Cameroon.

Corresponding author: Mbarga M. J. Arsène, e-mail: josepharsenembarga@yahoo.fr

Co-authors: IVP: podoprigora_iv@pfur.ru, AKLD: Davarsene@yahoo.com, MR: razanma3rouf@gmail.com, MSD: Milanadas@yandex.ru, ANS: senyagin-an@rudn.ru

Received: 05-02-2021, Accepted: 23-04-2021, Published online: 27-05-2021

doi: www.doi.org/10.14202/vetworld.2021.1330-1341 How to cite this article: Arsène MMJ, Podoprigora IV, Davares AKL, Razan M, Das MS, Senyagin AN (2021) Antibacterial activity of grapefruit peel extracts and green-synthesized silver nanoparticles, Veterinary World, 14(5): 1330-1341.

\begin{abstract}
Background and Aim: The gradual loss of efficacy of conventional antibiotics is a global issue. Plant material extracts and green-synthesized nanoparticles are among the most promising options to address this problem. Therefore, the aim of this study was to assess the antibacterial properties of aqueous and hydroalcoholic extracts of grapefruit peels as well as their inclusion in green-synthesized silver nanoparticles (AgNPs).

Materials and Methods: Aqueous and hydroalcoholic extracts $(80 \% \mathrm{v} / \mathrm{v})$ were prepared, and the volume and mass yields were determined. The synthesis of AgNPs was done in an eco-friendly manner using $\mathrm{AgNO}_{3}$ as a precursor. The nanoparticles were characterized by ultraviolet-vis spectrometry and photon cross-correlation spectroscopy. The antibacterial activity of the extracts was tested on three Gram-positive bacteria (Staphylococcus aureus ATCC 6538, clinical Enterococcus faecalis, and $S$. aureus) and two Gram-negative bacteria (two clinical Escherichia coli) using various concentrations of extracts (100, $50,25,12$, and $5 \mathrm{mg} / \mathrm{mL}$ and $5 \%$ dimethyl sulfoxide as negative control). Minimum inhibitory concentration (MIC) and minimum bactericidal concentration (MBC) were determined using the microdilution method. Modulation of cefazoline and ampicillin on resistant $E$. coli and $S$. aureus strains was added to the mixture design response surface methodology with extreme vertices design, with the diameters of inhibition and the fractional inhibitory concentration index as responses and factors, respectively. The antibiotic, the ethanolic extract, and water varied from $0.1 \mathrm{MIC}$ to $0.9 \mathrm{MIC}$ for the first two and from 0 to 0.8 in proportion for the third. Validating the models was done by calculating the absolute average deviation, bias factor, and accuracy factor.
\end{abstract}

Results: The volume yield of the EE and aqueous extract (AE) was $96.2 \%$ and $93.8 \%(\mathrm{v} / \mathrm{v})$, respectively, whereas their mass yields were $7.84 \%$ and $9.41 \%(\mathrm{~m} / \mathrm{m})$, respectively. The synthesized AgNPs were very uniform and homogeneous, and their size was dependent on the concentration of $\mathrm{AgNO}_{3}$. The antibacterial activity of the two extracts was dose-dependent, and the largest inhibition diameter was observed for the Gram-positive bacteria (S. aureus ATCC 6538; AE, 12; EE, 16), whereas AgNPs had a greater effect on Gram-negative bacteria. The MICs $(\mathrm{mg} / \mathrm{mL}$ ) of the AEs varied from 3.125 (S. aureus ATCC 6538) to 12.5 (E. coli 1 and E. coli 2), whereas the MICs of the EEs varied from 1.5625 (S. aureus 1, S. aureus ATCC 6538, and $E$. faecalis) to 6.25 (E. coli 1 ). There was a significant difference between the MICs of AEs and EEs ( $\mathrm{p}=0.014)$. The MBCs (mg/mL) of the AEs varied from 12.5 (S. aureus ATCC 6538) to 50 (S. aureus 1), whereas those of the EEs varied from 6.25 (S. aureus 1 ) to 25 (E. coli 1 and E. faecalis). Ethanolic grapefruit extracts demonstrated an ability to modulate cefazolin on E. coli and $S$. aureus but were completely indifferent to ampicillin on E. coli.

Conclusion: Grapefruit peel extracts and their AgNPs exhibit antibacterial properties that can be exploited for the synthesis of new antimicrobials and their EEs may be efficiently used synergistically with other antibiotics against bacteria with intermediate susceptibility.

Keywords: antimicrobials, grapefruit peel, green synthesis, plant extract, silver nanoparticles.

\section{Introduction}

The year 2020 will be remembered as the year of the pandemic because of Coronavirus Disease and its multi-dimensional catastrophic effects on human lives, with more than 100 million cases and 2.1 million

Copyright: Arsène, et al. Open Access. This article is distributed under the terms of the Creative Commons Attribution 4.0 International License (http://creativecommons.org/licenses/by/4.0/), which permits unrestricted use, distribution, and reproduction in any medium, provided you give appropriate credit to the original author(s) and the source, provide a link to the Creative Commons license, and indicate if changes were made. The Creative Commons Public Domain Dedication waiver (http://creativecommons.org/ publicdomain/zero/1.0/) applies to the data made available in this article, unless otherwise stated. deaths, and its impact on the global economy. This crisis has elicited a unanimous and unprecedented political and social response around the world [1]. However, countries should also pay attention to other silent epidemics, such as resistance to antibiotics, which is constantly growing in medicine, agriculture, and animal breeding. Recent estimates have shown that antibiotic resistance is responsible for 700,000 annual deaths worldwide, 230,000 of which have resulted from multidrug-resistant tuberculosis [2]. The World Health Organization estimates that if nothing is done to address this problem, drug-resistant diseases 
may cause 10 million deaths each year by 2050 and damage to the economy as catastrophic as the 20082009 global financial crisis [2]. Furthermore, economically (linked directly or not to agriculture and animal breeding), antimicrobial resistance could force up to 24 million people into extreme poverty by 2030 [2].

Antibiotic resistance is defined as the ability of bacteria to resist the inhibitory or destructive activity of an antibiotic to which it was initially sensitive [3]. It primarily results from the uncontrolled use of antibacterial drugs both in medicine and in agriculture, which leads to the recurrent exposure of bacteria to sub-lethal doses of antibiotics and results in their adaptation. This adaptation phenomenon results mainly from the enzymatic degradation of antibiotics by bacteria [4], the modification of the antibiotic target [5], change in membrane permeability [6], and alternative metabolic pathways [6]. Interbacterial transmission of antibiotic resistance through horizontal gene transfer (conjugation, transduction, and transformation) has made the situation critical worldwide [3]. To overcome this problem, intensive research has been done in recent years, and the use of plant extracts and nanoparticle has emerged as promising alternatives [6-13]. Medicinal herbs and plant extracts have been successfully used in traditional medicine around the world for millennia [14], and herbal remedies have various advantages because of their availability, fewer reported side effects, cost, high tolerance toward patients, and lack of bacterial resistance [15].

In addition to well-known medicinal plants, researchers have investigated the antibacterial activity of extracts from certain by-products of food consumption and synthesized green nanoparticles to valorize them in the search for new antimicrobials that may overcome antibiotic resistance [16-25]. Therefore, the aim of this study was to assess the antibacterial properties of aqueous and hydroalcoholic extracts of grapefruit peels as well as their inclusion in green-synthesized silver nanoparticles (AgNPs).

\section{Materials and Methods}

\section{Ethical approval}

Ethical approval was not required for this study. All the experiments were performed in vitro.

\section{Study period and location}

This study was conducted from October 2020 to January 2021 at the Laboratory of Microbiology and Virology of the Medical Institute of the People's Friendship University of Russia, Moscow, Russia.

\section{Material}

\section{Plant materials}

Fresh grapefruits were purchased from a local market in Moscow, washed with distilled water, and dried by wiping with clean papers. The peels were removed and ground with an electric blender into uniform fine particles. Ground peels were directly subjected to the extraction process.

\section{Bacterial strains}

The bacteria used in this study consisted of three Gram-positive bacteria (one clinical Staphylococcus aureus and one Enterococcus faecalis and a standard strain S. aureus ATCC 6538) and two Gram-negative strains (two clinical Escherichia coli). All strains were provided by the Department of Microbiology and Virology of the Peoples' Friendship University of Russia.

\section{Chemicals and media}

Silver nitrate $\left(\mathrm{AgNO}_{3}\right)$ was obtained from PanReac AppliChem, and dimethyl sulfoxide (DMSO) was purchased from BDH Laboratories, VWR International Ltd., USA. The media were procured from HiMedia and all other reagents and chemicals used were of analytical grade.

\section{Methods}

\section{Antibiotic sensitivity test}

The modified Kirby-Bauer's disk method described by Mbarga et al. [26] was used to study the antibiotic sensitivity of the bacterial strains tested in this study, and the following eight antibiotics disks were used: Amoxicillin, $30 \mu \mathrm{g} /$ disk; ampicillin, $25 \mu \mathrm{g} / \mathrm{disk}$; cefazolin, $30 \mu \mathrm{g} / \mathrm{disk}$; cefazolin/clavulanic acid, 30/10 $\mu \mathrm{g} / \mathrm{disk} ; 30 \mu \mathrm{g} /$ disk; ceftriaxone, $30 \mu \mathrm{g} /$ disk; ciprofloxacin, $30 \mu \mathrm{g} /$ disk; and nitrofurantoin, $200 \mu \mathrm{g} /$ disk and trimethoprim, and $30 \mu \mathrm{g} /$ disk.

\section{Extraction}

A maceration technique was performed to extract the grapefruit peel as previously described [27]. Briefly, $30 \mathrm{~g}$ of ground grapefruit peel was added to $270 \mathrm{~mL}$ of each solvent (distilled water and $80 \%$ ethanol) in separate conical flasks. The flasks were covered tightly and shaken at $200 \mathrm{rpm}$ for $24 \mathrm{~h}$ at $25^{\circ} \mathrm{C}$ in a shaking incubator (Heidolph Inkubator 1000 coupled with Heidolph Unimax 1010, Germany). The mixtures were then filtered by vacuum filtration using Whatman filter paper No. 1 and concentrated at $40^{\circ} \mathrm{C}$ in a rotary evaporator (IKA RV8) equipped with a water bath (IKA HB10) (IKA Werke, Staufen, Germany) and a vacuum pumping unit (IKA MVP10) (IKA Werke, Staufen, Germany). To avoid loss, the extracts were collected when the volumes were small enough, placed into Petri dishes previously weighed, and incubated open at $40^{\circ} \mathrm{C}$ until complete evaporation. The final dried crude extracts were weighed, the extraction yields were calculated, and $2 \mathrm{~g}$ of each extract was dissolved in $20 \mathrm{~mL}$ of $5 \%$ DMSO to obtain a concentration of $100 \mathrm{mg} / \mathrm{mL}$. The extracts were sterilized by microfiltration $(0.22 \mu \mathrm{m})$ and stored as a stock solution at $4^{\circ} \mathrm{C}$.

\section{Screening of antibacterial activity of the extracts}

The stock solutions were diluted to obtain concentrations of 5,25 , and $50 \mathrm{mg} / \mathrm{mL}$, and the well diffusion method on Mueller-Hinton Agar (MHA) was employed to test the antibacterial activity of the stock solutions and dilutions on overnight cultures of 
E. coli $1, E$ coli $2, S$. aureus 1 , and $S$. aureus ATCC 6538 adjusted to McFarland 0.5 (corresponding to approximately $1 \times 10^{8} \mathrm{cfu} / \mathrm{mL}$ ). The $5 \%$ DMSO was used as a negative control, and the results for the inhibition diameters represented the mean of three repetitions.

\section{Green synthesis of AgNPs}

AgNPs were green-synthesized according to the method described by Scolaro et al. [11] with slight modification. Briefly, $1 \mathrm{~mL}$ of the aqueous extract (AE) was added to $9 \mathrm{~mL}$ of freshly prepared $\mathrm{AgNO}_{3}$ at different concentrations $(0,0.625,1,1.25,2.5,5$, and $10 \mathrm{mM})$. The mixture was shaken in the dark at $60^{\circ} \mathrm{C}$ and $200 \mathrm{rpm}$. The color change of the solution from pale yellow to reddish-brown after 30 min indicated the reduction of $\mathrm{Ag}^{+}$ions to $\mathrm{Ag}^{0}$ nanoparticles.

\section{Characterization of green-synthetized AgNPs}

After visual observation, the biosynthesis of the AgNPs in a solution was monitored by measuring the ultraviolet (UV)-vis spectra of the reaction mixture. UV-vis spectra were recorded on a PerkinElmer Lambda 950 spectrophotometer from 35 to $800 \mathrm{~nm}$ at a resolution of $1 \mathrm{~nm}$. The solution without extract was used as a blank. Particle sizes were analyzed with photon cross-correlation spectroscopy (Sympatec $\mathrm{GmbH}$, Clausthal, Germany). A Nanophox instrument with UVette cuvettes (routine pack, Sympatec GmbH) was used. Single samples were measured 3 times at $25^{\circ} \mathrm{C}$. Data from the unique measurements were integrated to produce a single distribution with the PCCS Windox 5 software (Sympatec $\mathrm{GmbH}$ ) and the size distributions were obtained using the non-negative least squares algorithm. Standard latex samples (20 $\pm 2 \mathrm{~nm}$ ) (Sympatec $\mathrm{GmbH}$ ) and blank samples were analyzed before the measurements to ensure a high accuracy of the measurements.

\section{Antibacterial activity of AgNPs}

The AgNPs solutions prepared with different concentrations of $\mathrm{AgNO}_{3}$ were centrifuged at $12,000 \mathrm{rpm}$ for $45 \mathrm{~min}$, and the resulting pellets were washed twice with distilled water followed by ethanol. The pellets were dried at room temperature $\left(25^{\circ} \mathrm{C}\right)$, and $0.15 \mathrm{mg}$ was dissolved in $1.5 \mathrm{~mL}$ of distilled water to obtain a concentration of $100 \mu \mathrm{g} / \mathrm{mL}$. The mixtures were sterilized by microfiltration, and the antibacterial activity was determined as described above for plant extracts.

\section{Determination of minimum inhibitory concentra- tion (MIC) and minimum bactericidal concentration (MBC)}

The MIC of the extracts and green-synthesized AgNPs (synthesized with $1 \mathrm{mM}$ of $\mathrm{AgNO}_{3}$ ) on the five bacteria tested was determined using the microbroth dilution method as previously described [28]. Briefly, all stock solutions described above were subject to serial twofold dilution in Brain Heart Infusion broth sterile U-bottom 96-well microplates (Figure-1). Next, $100 \mu \mathrm{L}$ of broth was added to all the wells of the

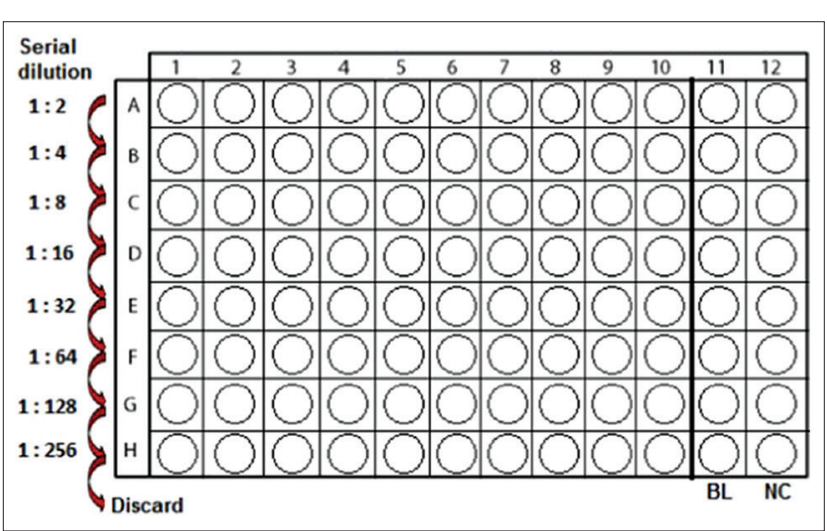

Figure-1: Serial dilution process in microbroth dilution method [28].

plates, and $100 \mu \mathrm{L}$ of extract $(100 \mathrm{mg} / \mathrm{mL})$ or AgNPs $(100 \mu \mathrm{g} / \mathrm{mL})$ was added to the first row. Then, $100 \mu \mathrm{L}$ of 5\% DMSO was added to columns 11 and 12 . Serial dilutions were performed by transferring $100 \mu \mathrm{L}$ from the wells of row A to the wells of row B and so forth, resulting in the concentrations shown in Figure-1. For each test well, $10 \mu \mathrm{L}$ of the respective inoculum was added (with turbidity equivalent to a $0.5 \mathrm{McF}$ arland scale). For column $11,10 \mu \mathrm{L}$ of saline solution was added $(0.9 \%)$, and this served as a positive control. For column 12, $10 \mu \mathrm{L}$ of inoculum was added, which served as a negative control. Finally, the plates were covered and incubated at $37^{\circ} \mathrm{C}$ for $24 \mathrm{~h}$. After incubation, MIC was considered the lowest concentration of the tested material that inhibited the visible growth of the bacteria. MBCs were determined by subculturing the wells without visible growth (with concentrations $\geq$ MIC) on MHA plates. Inoculated agar plates were incubated at $37^{\circ} \mathrm{C}$ for $24 \mathrm{~h}$. MBC was considered the lowest concentration that did not yield any bacterial growth on agar.

Antibiotic modulation: experimental design, modeling, validation of the model, and optimization

Modulations of ampicillin and cefazoline were performed with ethanolic extracts (EEs) of grapefruit peel on the E. coli 2 (resistant to ampicillin) and $S$. aureus 1 strains (intermediate sensitivity to cefazolin) and E. coli 2 (resistant to cefazolin). The checkerboard method, commonly used for the determination of synergy between the antibiotics and natural antibacterial compounds, was used for the antibiotic modulation assay. The fractional inhibitory concentration (FIC) index was calculated, as described by Trabelsi et al. [29]. Briefly, the individual MICs of the two antibiotics (MIC-ATB) and the EE (MICextr) on the targeted strains were first determined using the microdilution method as described above. Then, the new MIC values (MIC'-ATB and MIC'-extr) were determined after combining the two substances. To assess the interaction between the antibiotic and the natural extract, the FIC was determined using the formula: $F I C=F I C A+F I C B$, with: $F I C A=\frac{M I C A T B}{M I C A T B}$ 
and $F I C B=\frac{M I C \text { extr }}{M I C \text { extr }}$. The FIC index was inter-

preted as follows FIC $\leq 0.5$, synergy; $0.5 \leq$ FIC $\leq 1$, addition of effects; $1 \leq \mathrm{FIC} \leq 4$, indifference and for FIC >4, Antagonism.

Mixture design response surface methodology (MDRSM) with extreme vertices design was used to carry out the experiments to model and optimize the FIC index and the inhibition diameter of each combination. The independent variables (factors) were (A) concentration of antibiotic (cefazolin [Plan 1] or ampicillin [Plan 2]); (B) concentration of EE of grapefruit peel; and $(\mathrm{C})$ distilled water. The intervals of these factors were $10 \%$ MIC to $90 \%$ MIC for both antibiotic and $\mathrm{EE}$ and $0 \%-80 \%$ for distilled water (Figure-2). The interval values of the factors were chosen considering the literature on the modulation of antibiotics with other plant extracts.

Mathematical models describing the relationships among the modulation-dependent variable and the independent variables in a second-order equation were developed [30].

Design-based experimental data were matched according to the following second-order polynomial equation:

$$
Y=\beta_{0}+\sum_{i=0}^{k} \beta_{i} x_{i}+\sum_{i=0}^{k} \beta_{i i} x_{i}^{2}+\sum \sum_{i<j}^{k} \beta_{i j} x_{i} x_{j}+\varepsilon
$$

where $Y$ is the response, $x_{\mathrm{i}}$ and $x_{\mathrm{i}}$ are the variables, $\beta_{0}$ is the constant, $\beta_{\mathrm{i}}$ is the coefficient of the linear terms, $\beta_{\mathrm{ii}}$ is the coefficient of the quadratic terms, and $\beta_{\mathrm{ij}}$ is the coefficient of the interaction terms.

The coefficients of the models and statistical analysis (analysis of variance) were obtained using the

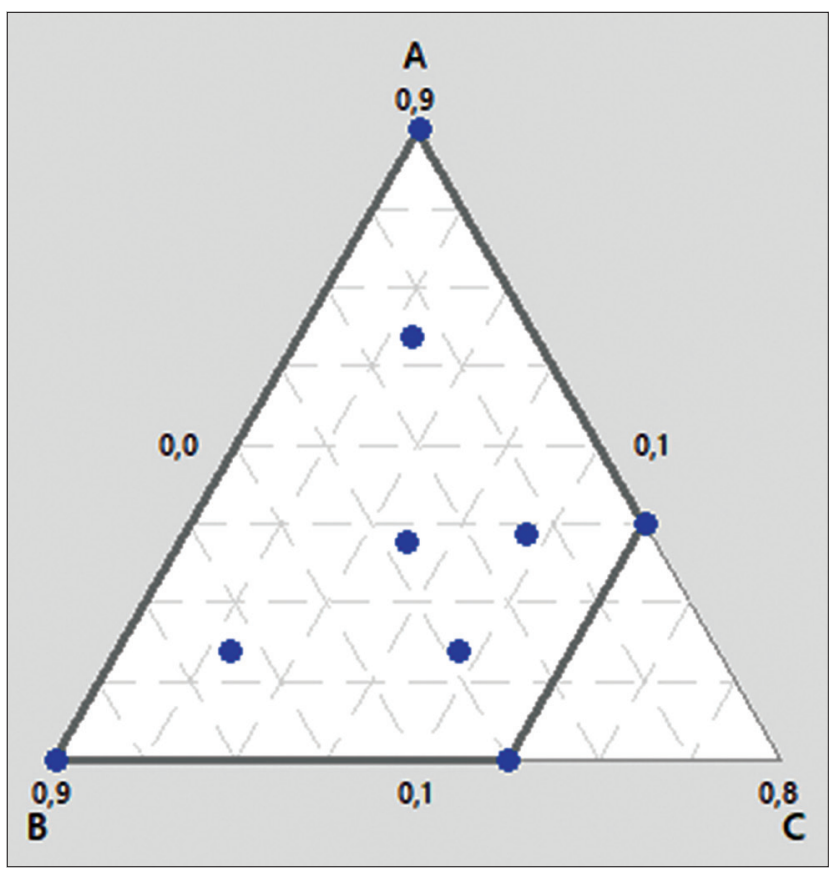

Figure-2: Simplex design plot in amounts, $A=$ Cefazolin; $\mathrm{B}=$ Ethanolic extract of grapefruit peel, $\mathrm{C}=$ Distilled water.
Minitab version 18 software (Minitab, Ltd., Brandon Court, Unit E1-E2 Progress Way, Coventry, CV3 2TE, UK). The curves were plotted using Sigmaplot version 12.1 (Systat Software, Inc., 1735 Technology Drive, Suite 430, San Jose, CA 95110, USA).

Validating the models was obtained by calculating the absolute average deviation (AAD), the bias factor $(B \mathrm{f})$, and the accuracy factor $\left(A_{\mathrm{f}}\right)[30,31]$, which were obtained as follows:

$$
\begin{gathered}
A_{f i}=10^{\frac{1}{N} \sum_{i=0}^{N}\left|\log \left(\frac{Y_{i, c a l}}{Y_{i, \text { exp }}}\right)\right|}, \\
B_{f i}=10^{\frac{1}{N} \sum_{i=0}^{N} \log \left(\frac{Y_{i, \text { cal }}}{Y_{i, \text { exp }}}\right)} \\
A A D=\frac{\left[\sum_{i=1}^{N}\left(\frac{\left|Y_{i, \text { exp }}-Y_{i, \text { cal }}\right|}{Y_{i, \text { exp }}}\right)\right]}{N}
\end{gathered}
$$

where $Y_{\mathrm{i}, \text { exp }}$ and $Y_{\mathrm{i}, \mathrm{cal}}$ are, respectively, experimental and calculated responses and $N$ is the number of experiments used in the calculation.

Each linear, interaction, and quadratic contribution of each factor were obtained as follows:

For linear terms,

$$
\text { Contribution (\%) }=\frac{\left|\beta_{i}\right|}{\sum_{i=1}^{k}\left|\beta_{i}\right|+\sum_{i=1}^{k}\left|\beta_{i i}\right|+\sum \sum_{i<j}^{k}\left|\beta_{i, j}\right|}
$$

For quadratic terms,

$$
\text { Contribution (\%) }=\frac{\left|\beta_{i i}\right|}{\sum_{i=1}^{k}\left|\beta_{i}\right|+\sum_{i=1}^{k}\left|\beta_{i i}\right|+\sum \sum_{i<j}^{k}\left|\beta_{i, j}\right|}
$$

For interaction terms,

$$
\text { Contribution (\%) }=\frac{\left|\beta_{i j}\right|}{\sum_{i=1}^{k}\left|\beta_{i}\right|+\sum_{i=1}^{k}\left|\beta_{i i}\right|+\sum \sum_{i<j}^{k}\left|\beta_{i j}\right|}
$$

Finally, optimization was done using the software Minitab 18 (Minitab, Ltd.). The conditions fixed were to maximize the inhibition diameter and to minimize the FIC index.

\section{Statistical analysis}

All experiments were carried out in triplicate. The inhibition diameters measured in the antibiotic sensitivity test were interpreted according to the Clinical and Laboratory Standards Institute [32]. Resistance $\mathrm{R}$, Intermediate $\mathrm{I}$, and Sensitive $\mathrm{S}$ interpretations were obtained automatically using algorithms written in Excel software [Microsoft Office 2016 MSO version 16.0.13628.20128(32 bits), USA]. The statistical significance was set at $\mathrm{p} \leq 0.05$. A t test and principal component analysis (PCA) were carried out using XLSTAT 2020 (Addinsof Inc., New York, USA) statistical software. PCA was done to visualize the correlations between the MICs, MBCs, and the bacteria tested. 


\section{Results and Discussion}

\section{Sensitivity of bacteria to antibiotics}

The sensitivity of the five bacteria used in this study (E. coli 1, E. coli 2, S. aureus 1, S. aureus ATCC 6538, and E. faecalis) to eight antibiotics was determined (Table-1) and the multidrug resistance (MDR) index of each bacterium was calculated. The standard strain, $S$. aureus ATCC 6538, was sensitive to all of the antibiotics tested $(\mathrm{MDR}=0)$, whereas the clinical $S$. aureus 1 strain was resistant to trimethoprim and cefazolin plus clavulanic acid (MDR=0.25). The phenotypic resistance of the $S$. aureus 1 clinical strain may have resulted from resistance acquired through exposure to various antimicrobials. In addition, the E. coli 1 and $E$. coli 2 strains were both resistant to ampicillin, amoxicillin, and trimethoprim, whereas only E. coli 1 was resistant to cefazoline and ceftriaxone. This result is consistent with that obtained by various authors on the resistance of clinical strains to antibiotics [33-35]. The problem of antibiotic resistance exists worldwide and affects all sectors that use antibiotics [34]. Various means have been implemented in recent years to provide effective solutions to this problem, and the studies carried out target bacteria that are resistant or not. The present study focused on evaluating the antibacterial properties of grapefruit peel extracts, a byproduct, and its green-synthetized AgNPs.

\section{Extract yield}

The extraction of $30 \mathrm{~g}$ of grapefruit peel was carried out for $24 \mathrm{~h}$ at $25^{\circ} \mathrm{C}$ with continuous stirring in $270 \mathrm{~mL}$ of water and $270 \mathrm{~mL}$ of ethanol $80 \%(\mathrm{v} / \mathrm{v})$. The volume yield was $96.2 \%(\mathrm{v} / \mathrm{v})$ for the EE and $93.8 \%(\mathrm{v} / \mathrm{v})$ for the AE. Interestingly, the highest yield of crude extract was obtained from the AE (9.41\%; $2.823 \mathrm{~g}$ ), whereas $7.84 \%$ (2.352 g) was obtained with the EE. The extraction performance depends on several factors, including the extraction method, time, the solvents, and the quality of the equipment used. The extraction yield varies greatly between studies and similarly in our study. Some researchers have obtained aqueous extraction yields higher than the ethanolic yield [36,37], whereas others have made opposite observations [38,39].

\section{Visual observation, UV-vis spectroscopy, and AgNPs diameter}

In all experiments, the addition of grapefruit peal extract to an aqueous solution of silver nitrate led to a change in color of the solution from yellowish to reddish-brown with an accentuation of the color as the concentration of $\mathrm{AgNO}_{3}$ increased (Figure-3). It is well known that AgNPs exhibit a yellowish-brown color in an aqueous solution because of the excitation of surface plasmon vibrations in AgNPs [13]. AgNPs were synthesized at different concentrations of $\mathrm{AgNO}_{3}$ by keeping the volume of the aqueous grapefruit extract constant $\left(1 \mathrm{~mL}+9 \mathrm{~mL}\right.$ of $\left.\mathrm{AgNO}_{3}\right)$, and all the solutions obtained were analyzed by UV-vis at 350-800 nm (Figure-4). We noticed that the curves of the UV-vis spectra had all the same tendencies, but the optical density increased with the increase in the $\mathrm{AgNO}_{3}$ concentration, thus confirming the visual observation. Some authors have suggested that the increase in density means that the quantity of AgNPs synthesized increases, whereas others concluded that it was the result of an increase in the size of the nanoparticles. This second hypothesis was verified in our study because, as shown in Figure-5, the diameters of the nanoparticles measured by PCCS varied significantly depending on the concentration of $\mathrm{AgNO}_{3}$. Indeed, we obtained average hydrodynamic particle diameters, $50 \times$ of $436.13 \pm 13.56 \mathrm{~nm}$ (Figure-5a), $375.29 \pm 4.97 \mathrm{~nm}$ (Figure-5b), 238.01 $\pm 8.96 \mathrm{~nm}$

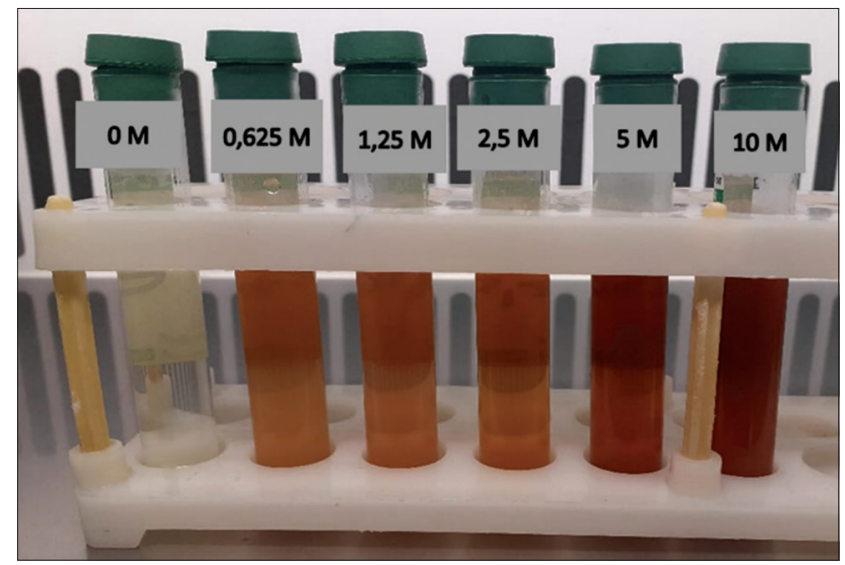

Figure-3: Coloration of solution after green-synthesis of silver nanoparticles with various concentrations of $\mathrm{AgNO}_{3}$.

Table-1: Sensibility of bacteria to antibiotics.

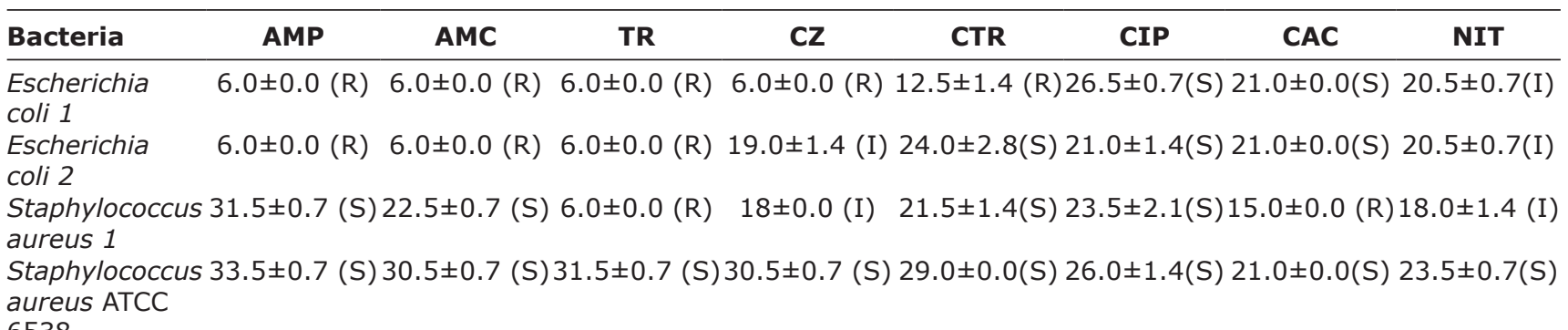
6538

Enterococcus $29.0 \pm 0.0$ (S) $22.0 \pm 1.4$ (S) $23.0 \pm 2.8$ (S) $30.5 \pm 2.1$ (S) $24.5 \pm 1.4$ (S) $25.5 \pm 2.1(\mathrm{~S}) 17.5 \pm 0.7$ (I) $20.0 \pm 1.4$ (I) faecalis 


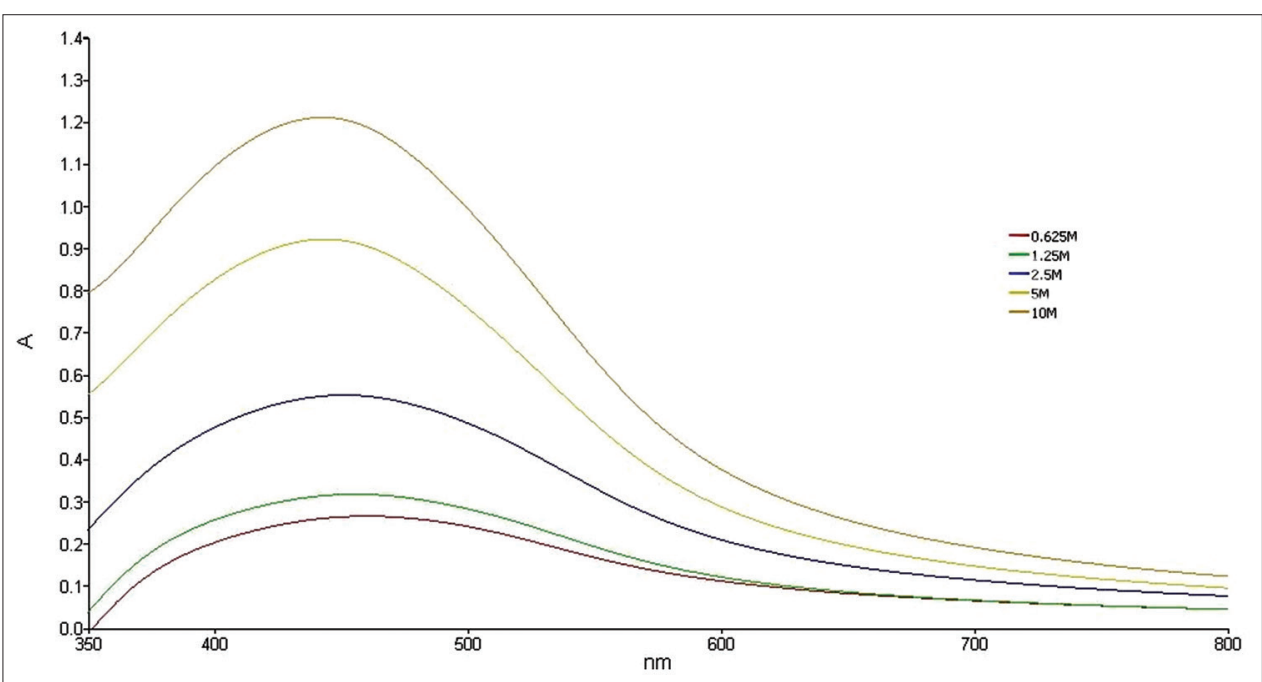

Figure-4: Ultraviolet-Vis of silver nanoparticles synthetized.

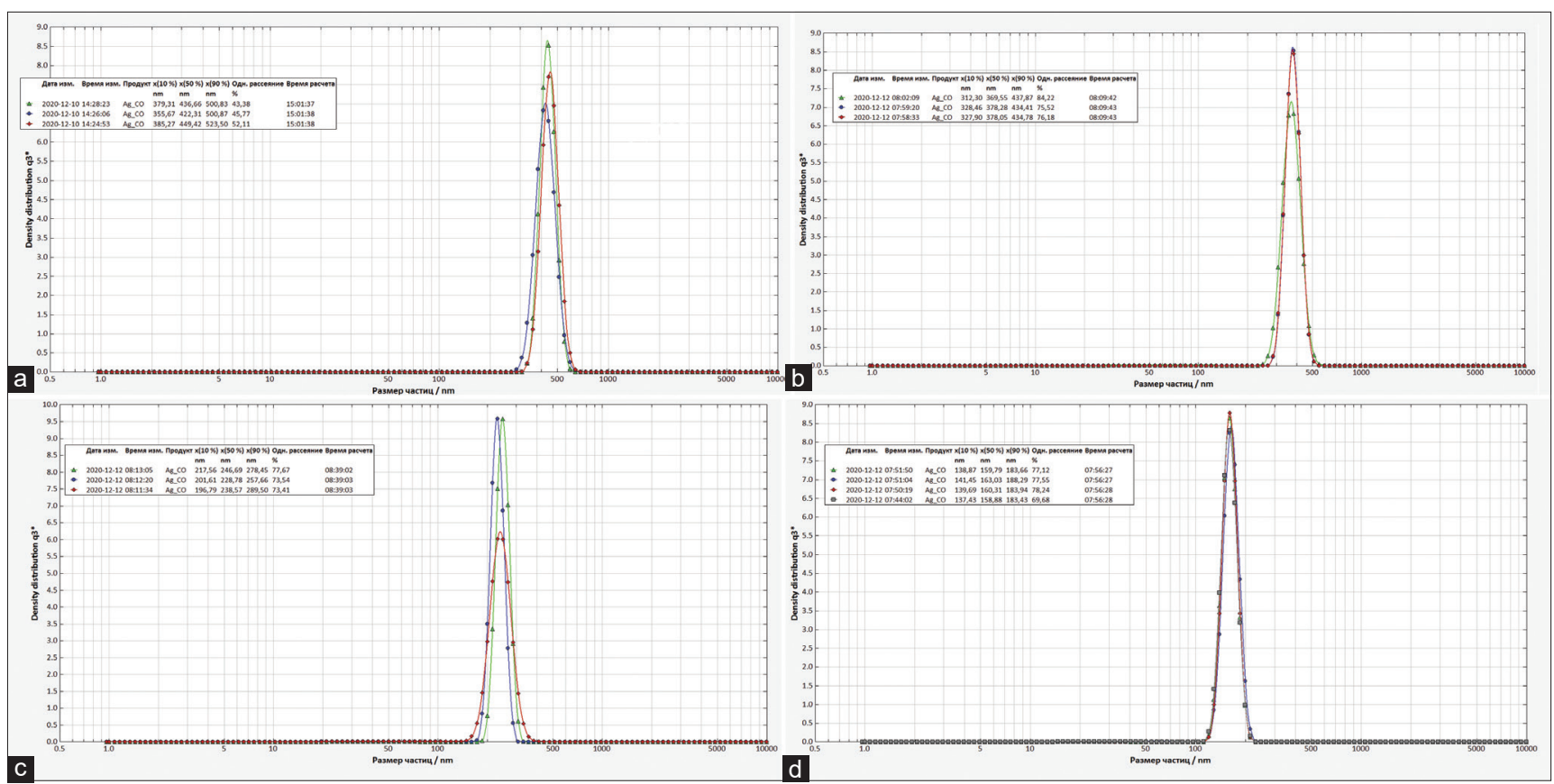

Figure-5: Diameter of particles and silver nanoparticles green synthetized with various concentrations of $\mathrm{AgNO}_{3}, 10 \mathrm{Mm}^{\prime}$ (a), $5 \mathrm{mM}$ (b), $2.5 \mathrm{mM}$ (c), and $1 \mathrm{mM}$ (d).

(Figure-5c), and 160.5 $\pm 1.74 \mathrm{~nm}$ (Figure-5d), respectively, with $\mathrm{AgNO}_{3}$ concentrations of 10, 5, 2.5, and 1 $\mathrm{mM}$. Conventionally, nanoparticles are defined as particles having a diameter ranging from 0 to $100 \mathrm{~nm}$ [40]. However, recent studies have generated particles with sizes of 145 [41], 150 [42], 160 [11,12], 175 [43], and $180 \mathrm{~nm}$ [44] as AgNPs. That is why we considered silver particles of $160.5 \mathrm{~nm}$ size green-synthesized with $1 \mathrm{mM}$ of $\mathrm{AgNO}_{3}$ as AgNPs in the remainder of the study. Although several methods, such as microwave irradiation, milling, or ultrasonication, are sometimes used to reduce the size of nanoparticles, they were not applied in this study to remain within the framework of strictly green synthesis. Moreover, concerning absorbances, the results were similar to data reported in the literature showing the optimal absorbance between 430 and $450 \mathrm{~nm}$ for AgNPs synthesized with various plant extracts with $\mathrm{AgNO}_{3}$ as a precursor [10-13]. In addition, we noticed in the UV-vis spectra that the curves obtained were all uniform, which shows a certain uniformity in the composition of the solutions. This observation was confirmed when measuring the diameters of the AgNPs and studying the distribution of the nanoparticles by PCCS. Overall, we conclude that, despite the relatively large size of the AgNPs synthesized in this study, grapefruit peel extract can contribute to the synthesis of AgNPs with good distribution and homogeneity.

\section{Antibacterial activity of grapefruits peel extracts and green-synthetized AgNPs}

Grapefruit peel ethanolic and AEs were evaluated for their antibacterial activity against five bacteria, including three Gram-positive bacteria ( $S$. aureus 1, S. aureus ATCC 6538, and E. faecalis) and two 
strains of Gram-negative bacteria (E. coli 1 and E. coli 2 ) using the disk diffusion method. The results of the antimicrobial activity measured using the well diffusion method are shown in Figure- 6 for the aqueous and EEs and in Figure-7 for the AgNPs. As expected, 5\% DMSO as a negative control did not show an inhibition zone against any of the tested bacteria. The results revealed that the effects of both extracts (aqueous and ethanolic) were dose-dependent. Regardless of the bacterial strain tested and the type of extract used, the inhibition diameters decreased with a decrease in the concentration of the extract. Similar observations have been made in most studies investigating antibacterial properties, particularly of plant extracts, and antimicrobial compounds, more generally. Furthermore, no antibacterial activity was observed for concentrations $\geq 5 \mathrm{mg} / \mathrm{mL}$ of AE, whereas for the EE, an antibacterial effect was observed on the $S$. aureus ATCC 6538 strain. In addition, as shown in Figure-7, the synthesized AgNPs exhibited antibacterial activity on all bacteria tested with larger inhibition diameters on Gram-negative bacteria. This indicates that AgNPs are broad-spectrum antimicrobial agents. It is well known that AgNPs have a more bactericidal effect on Gramnegative bacteria than on Gram-positive bacteria. This may be due to the cell wall structure of Gram-negative bacteria, which differs from the structure of Grampositive bacteria with a thin layer of peptidoglycan, the presence of a periplasm, and ease of exchange on the plasma membrane [45]. AgNPs have been used over the past decades to prevent and treat various diseases and are well known as antimicrobial agents because of their strong biocidal effect against microorganisms [45]. Their exact mechanism of action

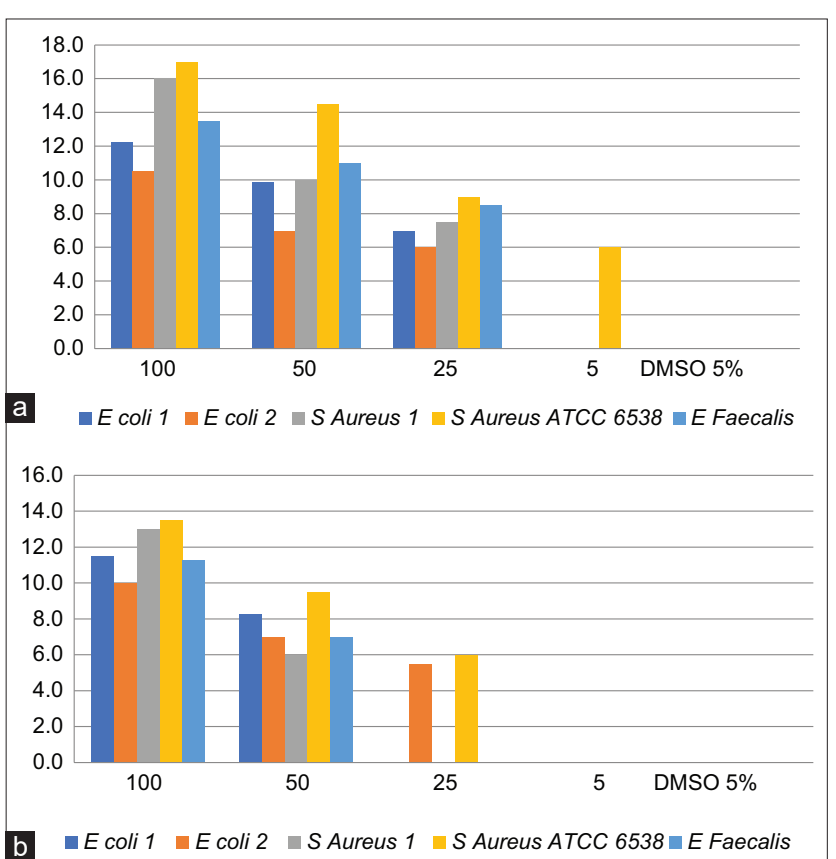

Figure-6: Results of the screening of the antimicrobial activity of the ethanolic (a) and aqueous (b) extracts of grapefruit peel. against bacteria is still largely unknown, although some researchers have suggested that their action on bacteria may result from their ability to adhere to the cytoplasmic membrane and cell wall to cause disruption and penetrate the cell [46], the formation of free radicals [45], the inactivation of proteins in the cell by silver ions [47], and the production of reactive oxygen species [45].

\section{MICs and MBCs of the extracts and green-synthe- tized AgNPs}

The MIC and MBC of the ethanolic and AEs of the grapefruit peels, as well as those of the green-synthetized AgNPs on the five bacterial strains (E. coli $1, E$. coli $2, S$. aureus $1, S$. aureus ATCC 6538, and E. faecalis) tested, are presented in Table-1. The MICs (expressed in $\mathrm{mg} / \mathrm{mL}$ ) of the AEs varied from 3.125 (S. aureus ATCC 6538) to 12.5 (E. coli 1 and E. coli 2 ), whereas the MICs of the EEs varied from 1.5625 (S. aureus $1, S$. aureus ATCC 6538, and E. faecalis) to 6.25 (E. coli 1 ). After determining the MICs using the microdilution method, the MBCs were confirmed by streaking the contents of the wells having a concentration greater than the MIC on MHA and choosing the lowest concentration where no growth was observed as the MBC. The MBCs $(\mathrm{mg} / \mathrm{mL})$ of the AEs varied from 12.5 (S. aureus ATCC 6538) to 50 (S. aureus 1), whereas those of the EEs varied from 6.25 ( $S$. aureus 1) to 25 (E. coli 1 and E. faecalis). A paired sample $\mathrm{t}$ test revealed that there was a significant difference between the MICs of the AEs and EEs $(p=0.014)$. This difference in activity between the two extracts may be explained by the fact that some bioactive components of medicinal plants may differ in their solubility depending on the solvents used for preparation [48]. Otherwise, the results of this study are similar to those of Özogul et al. [19], Deng et al. [21], and Presentato et al. [49]. A large variation in the MIC of grapefruit peel extract demonstrated in several investigations may result from considerable variation in the extraction method, chemical constituents, and bacterial strains tested. Overall, grapefruit peel extracts were more effective against Gram-positive than against Gram-negative bacteria. The higher sensitivity of Gram-positive bacteria compared with Gramnegative bacteria may be explained by the differences in the composition of their cell walls. Gram-positive bacteria have an outer wall made essentially of peptidoglycan, which is an ineffective permeability barrier [50], whereas the outer phospholipid membrane of Gram-negative bacteria makes the outer layer impermeable to lipophilic solutes and constitutes a selective barrier to hydrophilic solutes.

Although the nanoparticles synthesized in this study with $1 \mathrm{mM}$ of $\mathrm{AgNO}_{3}$ were relatively large $(160 \mathrm{~nm})$, their MICs and MBCs were determined (Table-1). The MICs of AgNPs ranged from $3.125 \mu \mathrm{g} / \mathrm{mL}$ (E. faecalis) to $50 \mu \mathrm{g} / \mathrm{mL}$ (S. aureus 1). Surprisingly, the MIC of the AgNPs on $S$. aureus ATCC $6538(6.25 \mu \mathrm{g} / \mathrm{mL})$ was far lower compared 


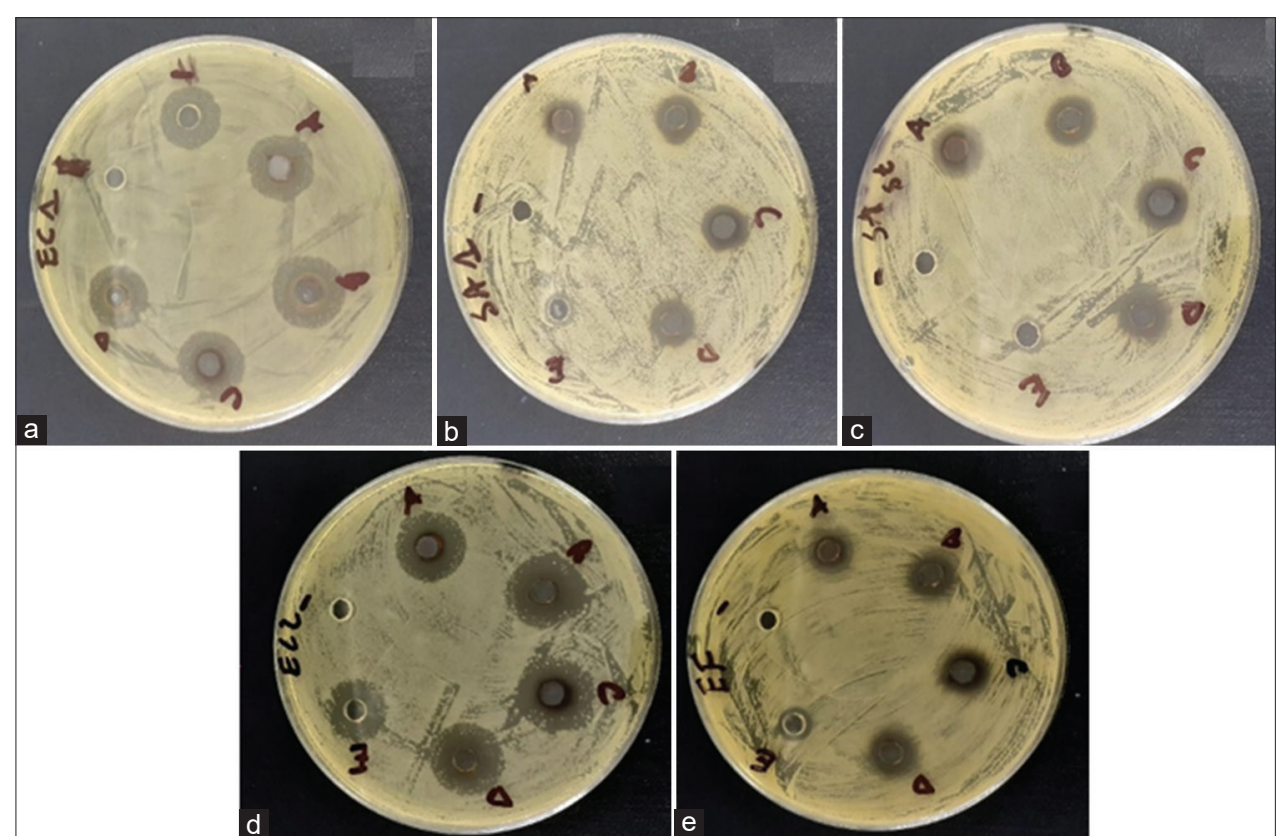

Figure-7: Antibacterial activity of silver particles and silver nanoparticles green-synthetized against Escherichia coli 1 (a), Staphylococcus aureus 1 (b), S. aureus ATCC 6538 (c) E. coli 2 (d), and Enterococcus faecalis (e).

with that of the clinical strain $S$. aureus 1, although the two strains belong to the same species. This observation raises new questions, including whether clinical strains, because of their history in different habitats and their exposure to various substances, can adapt to antimicrobial agents and even nanoparticles. On the one hand, Anuj et al. [51] revealed that the size of the bacteria had an influence on the effectiveness of the antimicrobials tested and microbes with a large surface area are more difficult to treat than small size microbes. Since the diameter of staphylococci generally varies from 0.5 to $1.5 \mu \mathrm{m}$, it may be necessary to conduct additional studies to assess the size of the two strains of $S$ aureus ( $S$. cereus 1 and $S$. aureus ATCC 6538) used in this study. However, the hypothesis of acquired resistance appears to be a more likely explanation for this observation. Indeed, Valentin et al. [52] revealed that exposure of bacteria to AgNPs can lead to mutations endowing these microbes with genotypic resistance traits that can be transmitted between bacteria similar to conventional antibiotics. Therefore, this phenomenon should be carefully monitored, and it suggests that nanoparticle antimicrobials should only be used when needed to maintain their effectiveness in treating infections [52]. Furthermore, AgNPs also exhibited bactericidal activity against $S$. aureus ATCC 6538, E. faecalis, and E. coli 1 , whereas the MBC of E. coli 2 and $S$. aureus 1 could not be determined because they were superior at the initial AgNP concentration that was prepared $(100 \mu \mathrm{g} / \mathrm{mL})$. To visualize the association between the microbial species tested in this study, the MICs and MBCs of the aqueous and EEs, a PCA was performed. Figure- 8 shows the distribution of the tested bacteria, MICs, and MBCs in an F1 × F2 system. The strains $S$. aureus ATCC 6538 and E. faecalis were relatively

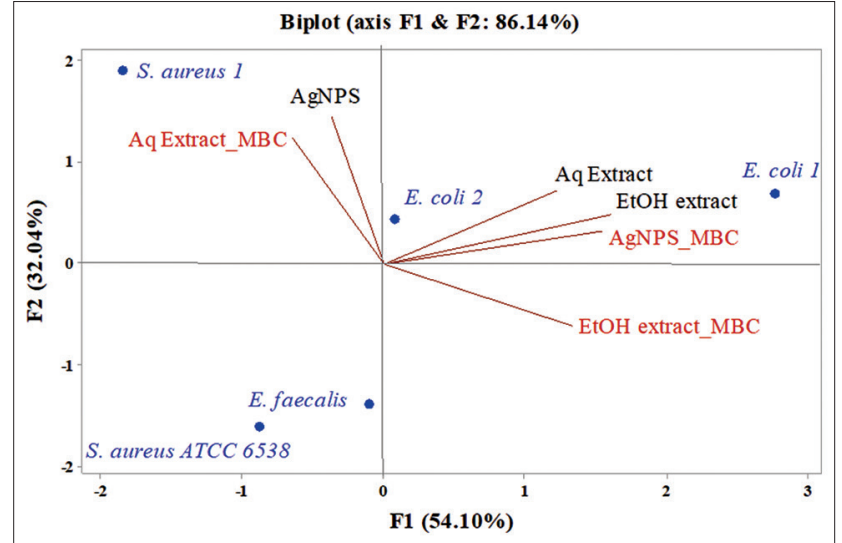

Figure-8: Principal component analysis of minimum inhibitory concentration and minimum bactericidal concentration of silver nanoparticles green-synthetized, aqueous, and ethanolic extract of grapefruit peel against Escherichia coli, Staphylococcus aureus and Enterococcus faecalis.

similar with respect to their sensitivity to the antimicrobials tested. The same similarity was verified in the two strains of E. coli (1 and 2) tested, whereas the $S$. aureus 1 strain appeared to exhibit the opposite result from the other bacteria. Moreover, the MICs of the aqueous and EEs were strongly correlated with the MBC of AgNPs, which was expected because the quantities of AgNPs necessary to have a significant antibacterial effect are always very low, whereas the quantities of plant extract necessary to obtain a similar antimicrobial effect depends on the plant used and are generally greater. Overall, the MIC and MBC results observed in this study suggest that grapefruit peels and its green-synthesized AgNPs can be exploited for their antibacterial properties in several sectors, including pharmaceuticals (for the development of 
new antimicrobials), medicine (for the treatment of bacterial infections), agriculture, and animal breeding. However, more studies are needed to determine the exact composition of the grapefruit peel extracts and to assess their toxicity and safety.

\section{Modulation of cefazolin and ampicillin with grape- fruit peel extract}

The use of combination therapy has been suggested as a new approach to improve the efficacy of antimicrobial agents by screening crude extracts from medicinal plants with good indications for use in combination with antibiotics [53]. In this study, the EE of grapefruit peel was used for the modulation of antibiotics since it demonstrated the best antibacterial effect. The modulation of ampicillin was tested on the E. coli 2 strain, which was resistant to ampicillin, whereas the modulation of cefazoline was tested on the $S$. aureus 1 strain, which showed intermediate sensitivity to this antibiotic, and on E. coli 2, which was resistant to cefazoline (Table-2). The MDRSM with extreme vertices design was used to assess and predict the FIC index and inhibition diameters resulting from each formulation on the bacteria tested. The three factors for this plan were the proportions of antibiotic (A), the EE of grapefruit peel (B), and distilled water (C), which varied from 0.1 MIC to 0.9 MIC for the first two factors and from 0 to 0.5 for distilled water. The role of distilled water was to complete the mixture to have the desired concentration of the antibacterial. The results are shown in Table-3. The combination of ampicillin and EE was completely indifferent to the resistant E. coli 2 strain. However, the combination of cefazolin and EE showed a synergistic effect and reduced MIC on E. coli 2 and S. aureus 2. Regarding the $E$. coli 2 strain, the results observed for the mixing plan indicated that there was a synergy between cefazolin and the ethanolic grapefruit extract for concentrations of cefazolin $\geq 0.375$ MIC combined with concentrations of the extracts $\geq 0.1 \mathrm{MIC}$. This result was closely correlated with the inhibition diameters obtained. In addition, for $S$. aureus 2, the synergistic action of the EE and cefazolin was modeled according to the monitoring of the diameters of inhibition (D) and the FIC index. The two models (D and FIC) were validated on the basis of the coefficient of determination $\mathrm{R}^{2}(0.95$ and 0.89$)$, AAD (0.005 and 0.082), the $B \mathrm{f}$ (1.005 and 1.003), and the $A_{\mathrm{f}}(1.000$ and 1.083). As shown in Figures-9 and 10, the resulting contour plots showed that there is a synergistic action (FIC $\leq 0.5$ ) for most of the formulations made between the limits of the proportions fixed in the study. However, when the proportion of water was very small or slightly high, additional effects of the two antimicrobials were observed $(0.5 \leq$ FIC $\leq 1)$. In addition, the very proportion of water-induced an indifference between cefazolin and the ethanolic grapefruit peel extract $(1 \leq$ FIC $\leq 4)$. Nevertheless, despite the formulation preparation between the limits of this study, no antagonistic effect between the two substances was observed (FIC $\geq 4$ ). Although a synergistic effect was observed in all

Table-2: MIC and MBC of silver nanoparticles green-synthetized, aqueous and ethanolic extract of grapefruit peel against Escherichia coli, Staphylococcus aureus, and Escherichia faecalis.

\begin{tabular}{|c|c|c|c|c|c|c|c|c|}
\hline \multirow[t]{2}{*}{ Bacteria } & \multicolumn{4}{|c|}{$\operatorname{MIC}(\mathbf{m g} / \mathbf{m L})$} & \multicolumn{4}{|c|}{ MBC (mg/mL) } \\
\hline & Aq extract & EtOH extract & $\mathbf{C Z}$ & AgNPs & Aq extract & EtOH extract & $\mathbf{C Z}$ & AgNPs \\
\hline Escherichia coli 1 & 12.5 & 6.25 & ND & 0.025 & 25 & 25 & ND & 0.5 \\
\hline Escherichia coli 2 & 12.5 & 3.125 & 0.025 & 0.025 & 25 & 12.5 & 0.1 & ND \\
\hline Staphylococcus aureus 1 & 6.25 & 1.5625 & 0.0125 & 0.05 & 50 & 6.25 & 0.1 & ND \\
\hline Staphylococcus aureus ATCC 6538 & 3.125 & 1.5625 & ND & 0.00625 & 12.5 & 12.5 & ND & 0.025 \\
\hline Enterococcus faecalis & 6.25 & 1.5625 & ND & 0.003125 & 25 & 25 & ND & 0.0125 \\
\hline
\end{tabular}

AgNPs=Silver nanoparticles, MIC=Minimum inhibitory concentration, MBC=Minimum bactericidal concentration

Table-3: Modulation of cefazolin with ethanolic extract of grapefruit peel.

\begin{tabular}{|c|c|c|c|c|c|c|c|c|c|c|c|c|c|c|c|}
\hline \multirow[t]{2}{*}{ Trials } & \multicolumn{3}{|c|}{ Proportion } & \multicolumn{3}{|c|}{ Initial concentration } & \multicolumn{3}{|c|}{ Volume $(\mathrm{mL})$} & \multicolumn{2}{|c|}{$\begin{array}{c}\text { Escherichia } \\
\text { coli } 2\end{array}$} & \multicolumn{4}{|c|}{ Staphylococcus aureus } \\
\hline & $\mathbf{C Z}$ & $\begin{array}{c}\text { EtOH } \\
\text { extract }\end{array}$ & $\mathrm{H}_{2} \mathrm{O}$ & $\begin{array}{l}\text { ATB } \\
(\mu g / \\
\mathrm{mL})\end{array}$ & $\begin{array}{c}\text { EtOH } \\
\text { extract } \\
(\mathrm{mg} / \mathrm{mL})\end{array}$ & $\mathrm{H}_{2} \mathrm{O}$ & ATB & EXTR & $\mathrm{H}_{2} \mathrm{O}$ & $\underset{(\mathrm{mm})}{\mathrm{D}}$ & FIC & $\begin{array}{l}D \text { exp } \\
(\mathrm{mm})\end{array}$ & $\begin{array}{l}\text { D cal } \\
(\mathrm{mm})\end{array}$ & $\begin{array}{l}\text { FIC } \\
\text { exp }\end{array}$ & $\begin{array}{l}\text { FIC } \\
\text { cal }\end{array}$ \\
\hline 1 & 0.9 & & 0 & MIC & MIC & - & 4.500 & & 0.000 & 15.00 & 0.08 & 34 & 33.68 & 0.13 & 0.12 \\
\hline 2 & 0.2375 & 0.6375 & 0.125 & MIC & MIC & - & 1.188 & 3.188 & 0.625 & 0 & $\mathrm{~N}$ & & 27.32 & 0.22 & 0.22 \\
\hline 3 & 0.1 & 0.4 & 0.5 & MIC & MIC & - & 0.500 & 2.000 & 2.500 & 0 & $\mathrm{~N}$ & 26 & 5.45 & 0.25 & 0.24 \\
\hline 4 & 0.375 & 0.375 & 0.25 & MIC & MIC & - & 875 & 1.875 & 1.250 & 0 & $\mathrm{NL}$ & 30 & 83 & 0.19 & 0.16 \\
\hline 5 & 0.3875 & 0.2375 & 0.375 & MIC & MIC & - & 1.938 & 1.188 & 1.875 & 8 & 0.17 & 30 & 30.62 & 0.16 & 0.14 \\
\hline 6 & 0.6375 & 0.2375 & 0.125 & MIC & MIC & - & 3.188 & 1.188 & 0.625 & 14 & 0.20 & 30 & 30.79 & 0.11 & 0.13 \\
\hline 7 & 0.1 & 0.9 & 0 & MIC & MIC & - & 0.500 & 4.500 & 0.000 & 0 & ND & 26 & 26.28 & 0.25 & 0.25 \\
\hline 8 & 0.4 & 0.1 & 0.5 & MIC & MIC & - & 2.000 & 0.500 & 2.500 & 10 & 0.10 & 29 & 28.54 & 0.13 & 0.13 \\
\hline 9 & 0.2375 & 0.3875 & 0.375 & MIC & MIC & - & 1.188 & 1.938 & 1.875 & 0 & ND & 30 & 29.49 & 0.16 & 0.19 \\
\hline
\end{tabular}

$\mathrm{MIC}=$ Minimum inhibitory concentration, $\mathrm{MBC}=$ Minimum bactericidal concentration, FIC=Fractional inhibitory concentration 


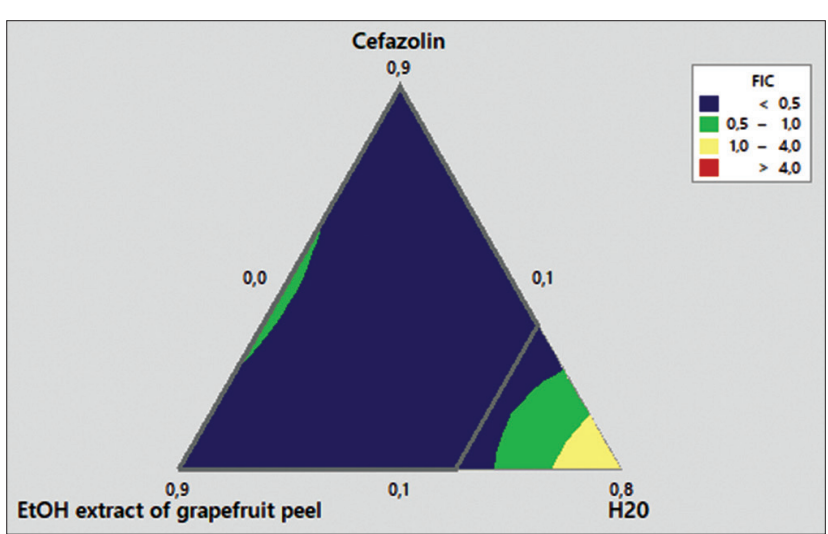

Figure-9: Response surface of fractional inhibitory concentration (FIC) index as function of proportion of cefazolin (A), ethanolic extract of grapefruit peel (B) and water (C) on Staphylococcus cereus 1. FIC $=0.0831 \mathrm{~A}+$ $0.2469 \mathrm{~B}+0.507 \mathrm{C}+0.227 \mathrm{AB}-0.85 \mathrm{AC}-0.42 \mathrm{BC}$.

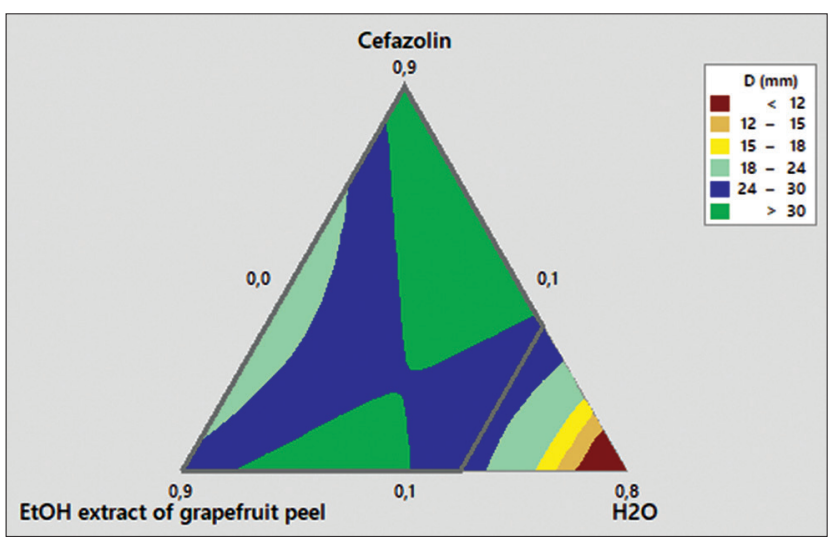

Figure-10: Response surface of inhibition diameter of Staphylococcus cereus 1 as function of Proportion of cefazolin $(A)$, ethanolic extract of grapefruit peel $(B)$ and water $(C D(\mathrm{~mm})=40.5 \mathrm{~A}+31.25 \mathrm{~B}-24 \mathrm{C}-65.5 \mathrm{AB}+$ 94.4AC +99BC.

formulations, optimization of the synergistic effect by minimizing the FIC and maximizing the diameters of inhibition revealed that the optimal synergistic effect was obtained with a mixture having proportions of $49 \%$ of cefazolin ( $0.49 \mathrm{MIC}), 22 \%$ of ethanolic grapefruit peels extract (0.22 MIC), and 29\% distilled water. Therefore, our results suggest that EEs of grapefruit peel may reduce the MIC of cefazolin on bacteria, including resistant strains. These extracts may act as a substrate to circumvent or inhibit the efflux pump contained in the S. aureus and E. coli strains. Similar observations have been reported with various plants; however, to the best of our knowledge, no similar study has been performed to date with grapefruit peel. The potent antibiotic potentiation activity of grapefruit peel suggests a use for extending the life of older antibiotics that have lost efficacy in fighting bacterial infections.

\section{Conclusion}

The results of this study suggest that grapefruit peels, a byproduct, possess compounds with antibacterial properties that may be used in the fight against antibiotic resistance and in the synthesis of new drugs for the treatment of bacterial diseases. Nevertheless, further studies are needed to evaluate the mechanisms of action and toxicity of these extracts. In addition, the AgNPs, although relatively large in size, were also successfully synthesized from grapefruit peel through a simple green and eco-friendly route. They exhibited antibacterial activity against both Gram-positive and Gram-negative bacteria with a greater effect on the latter. Similarly, further studies should be carried out to optimize the synthesis process of AgNPs with grapefruit peels by evaluating the parameters affecting size and to establish toxicity profiles.

\section{Authors' Contributions}

MMJA and AKLD: Conceptualized and designed the study. MMJA and ANS conducted the laboratory experiments. MMJA, AKLD, IVP, MR, and MSD: Wrote the first manuscript draft, edited, and revised the final version of the manuscript. All authors have read and approved the final manuscript.

\section{Acknowledgments}

This study has been supported by the RUDN University strategic Academic Leadership Program.

\section{Competing Interests} interests.

The author declares that they have no competing

\section{Publisher's Note}

Veterinary World remains neutral with regard to jurisdictional claims in published institutional affiliation.

\section{References}

1. Da Silva, J.B. Jr., Espinal, M. and Ramón-Pardo, P. (2020) Antimicrobial resistance: Time for action. Rev. Panam. Salud Publica, 44: e131.

2. World Health Organization. (2019) New Report Calls for Urgent Action to Avert Antimicrobial Resistance Crisis. World Health Organization, Geneva. Available from: https://www.who.int/news/item/29-04-2019-new-reportcalls-for-urgent-action-to-avert-antimicrobial-resistancecrisis. Retrieved on 28-01-2021.

3. Su, T., Qiu, Y., Hua, X., Ye, B., Luo, H., Liu, D. and Qiu, Z. (2020) Novel opportunity to reverse antibiotic resistance: To explore traditional Chinese medicine with potential activity against antibiotics-resistance bacteria. Front. Microbiol., 11: 3372 .

4. Elekhnawy, E., Sonbol, F., Abdelaziz, A. and Elbanna, T. (2020) Potential impact of biocide adaptation on selection of antibiotic resistance in bacterial isolates. Future $J$. Pharm. Sci., 6(1): 1-10.

5. Schaenzer, A.J. and Wright, G.D. (2020) Antibiotic resistance by enzymatic modification of antibiotic targets. Trends. Mol. Med., 26(8): 768-782.

6. Singh, A., Gautam, P.K., Verma, A., Singh, V., Shivapriya, P.M., Shivalkar, S. and Samanta, S.K. (2020) Green synthesis of metallic nanoparticles as effective alternatives to treat antibiotics resistant bacterial infections: A review. Biotechnol. Rep., 25: e00427.

7. Lopes, T.S., Fontoura, P.S., Oliveira, A., Rizzo, F.A., Silveira, S. and Streck, A.F. (2020) Use of plant extracts and essential oils in the control of bovine mastitis. Res. Vet. 
Sci., 131: 186-193.

8. Varijakzhan, D., Chong, C.M., Abushelaibi, A., Lai, K.S. and Lim, S.H.E. (2020) Middle Eastern plant extracts: An alternative to modern medicine problems. Molecules, 25(5): 1126.

9. Gardner, C.L., da Silva, D.R., Pagliai, F.A., Pan, L., PadgettPagliai, K.A., Blaustein, R.A. and Gonzalez, C.F. (2020) Assessment of unconventional antimicrobial compounds for the control of "Candidatus liberibacter asiaticus", the causative agent of citrus greening disease. Sci. Rep., 10(1): $1-15$.

10. Kim, G.W., Shin, D. and Yang, M. (2020) Optical property change of silver nanowire thin films in laser patterning process. Int. J. Precis. Eng. Manuf., 21(2): 301-308.

11. Scolaro, C., Visco, A. and Torrisi, L. (2020) Laser welding of polymeric nanocomposites filled with silver nanoparticles produced by laser ablation. J. Instrum., 15(2): C02037.

12. Długosz, O. and Banach, M. (2020) Continuous synthesis of metal and metal oxide nanoparticles in microwave reactor. Colloids Surf. A Physicochem. Eng., 606: 125453.

13. Kumar, R., Kumar, S., Jewaria, P.K. and Devi, P. (2020) A study on green synthesis of silver nanoparticles using Murraya koenigii aqueous leaf extract. Int. J. Commun. Syst., 8(2): 2757-2759.

14. Salmerón-Manzano, E., Garrido-Cardenas, J.A. and Manzano-Agugliaro, F. (2020) Worldwide research trends on medicinal plants. Int. J. Environ. Res. Public Health, 17(10): 3376.

15. Shaheen, G., Akram, M., Jabeen, F., Ali Shah, S. M., Munir, N., Daniyal, M. and Zainab, R. (2019) Therapeutic potential of medicinal plants for the management of urinary tract infection: A systematic review. Clin. Exp. Pharmacol. Physiol., 46(7): 613-624.

16. Ramli, A.N.M., Manap, N.W.A., Bhuyar, P. and Azelee, N.I.W. (2020), Passion fruit (Passiflora edulis) peel powder extract and its application towards antibacterial and antioxidant activity on the preserved meat products. $S N$ Appl. Sci., 2(10): 1-11.

17. Thi, T.U.D., Nguyen, T.T., Thi, Y.D., Thi, K.H.T., Phan, B.T. and Pham, K.N. (2020) Green synthesis of $\mathrm{ZnO}$ nanoparticles using orange fruit peel extract for antibacterial activities. RSC Adv., 10(40): 23899-23907.

18. Chollakup, R., Pongburoos, S., Boonsong, W., Khanoonkon, N., Kongsin, K., Sothornvit, R. and Harnkarnsujarit, N. (2020) Antioxidant and antibacterial activities of cassava starch and whey protein blend films containing rambutan peel extract and cinnamon oil for active packaging. $L W T, 130: 109573$.

19. Özogul, Y., Özogul, F. and Kulawik, P. (2021) The antimicrobial effect of grapefruit peel essential oil and its nanoemulsion on fish spoilage bacteria and food-borne pathogens. $L W T, 136: 110362$.

20. Jridi, M., Abdelhedi, O., Salem, A., Kechaou, H., Nasri, M. and Menchari, Y. (2020) Physicochemical, antioxidant and antibacterial properties of fish gelatin-based edible films enriched with orange peel pectin: Wrapping application. Food Hydrocoll., 103: 105688

21. Deng, W., Liu, K., Cao, S., Sun, J., Zhong, B. and Chun, J. (2020) Chemical composition, antimicrobial, antioxidant, and antiproliferative properties of grapefruit essential oil prepared by molecular distillation. Molecules, 25(1): 217.

22. Guo, C., Shan, Y., Yang, Z., Zhang, L., Ling, W., Liang, Y. and Zhang, J. (2020) Chemical composition, antioxidant, antibacterial, and tyrosinase inhibition activity of extracts from Newhall navel orange (Citrus sinensis Osbeck cv. Newhall) peel. J. Sci. Food Agric., 100(6): 2664-2674.

23. Nahar, K.N., Rahaman, M., Khan, G.M., Islam, M. and Al-Reza, S.M. (2021) Green synthesis of silver nanoparticles from Citrus sinensis peel extract and its antibacterial potential. Asian J. Green Chem., 5(1): 135-150.

24. Tshireletso, P., Ateba, C.N. and Fayemi, O.E. (2021) Spectroscopic and antibacterial properties of CuONPs from orange, lemon and tangerine peel extracts: Potential for combating bacterial resistance. Molecules, 26(3): 586.

25. Gesese, T.N., Fanta, S.W., Mersha, D.A. and Satheesh, N. (2021) Physical properties and antibacterial activity of cotton fabric treated with methanolic extracts of Solanum incanum fruits and red onion peels. J. Tex. Inst., 2020: 1-11.

26. Mbarga, M.J., Andreevna, S.L. and Viktorovna, P.I. (2020) Evaluation of apparent microflora and study of antibiotic resistance of coliforms isolated from the shells of poultry eggs in Moscow-Russia. J. Adv. Microbiol., 20(4): 70-77.

27. Najumudin, K., Ayubu, J. and Elnazeer, A.M. (2018) Antigiardial activity of some plant extracts used in traditional medicine in Sudan in comparison with metronidazole. Microbiology, 2(4): 75-82.

28. Veiga, A., da Graça, T.T.M., Rossa, L.S., Mengarda, M., Stofella, N.C., Oliveira, L.J. and Murakami, F.S. (2019) Colorimetric microdilution assay: Validation of a standard method for determination of MIC, IC $50 \%$, and IC $90 \%$ of antimicrobial compounds. J. Microbiol. Methods, 162: $50-61$

29. Trabelsi, A., El Kaibi, M.A., Abbassi, A., Horchani, A., Chekir-Ghedira, L. and Ghedira, K. (2020) Phytochemical study and antibacterial and antibiotic modulation activity of Punica granatum (Pomegranate) leaves. Scientifica, 2020: 8271203.

30. Ekorong, F.J.A., Zomegni, G., Desobgo, S.C.Z. and Ndjouenkeu, R. (2015) Optimization of drying parameters for mango seed kernels using central composite design. Bioresour. Bioprocess, 2(1): 8 .

31. Mbarga, M.J.A., Desobgo, S.C.Z., Tatsadjieu, L.N., Kavhiza, N. and Kalisa, L. (2021) Antagonistic effects of raffia sap with probiotics against pathogenic microorganisms. Foods Raw Mater., 9(1): 24-31.

32. NCCLs: Clinical and Laboratory Standards Institute. (2019) Control Methods. Biological and Microbiological Factors: Determination of the Sensitivity of Microorganisms to Antibacterial Drugs. Federal Centre for Sanitary and Epidemiological Surveillance of Ministry of Health of Russia. Clinical and Laboratory Standards Institute, Wayne, PA.

33. Dsani, E., Afari, E.A., Danso-Appiah, A., Kenu, E., Kaburi, B.B. and Egyir, B. (2020) Antimicrobial resistance and molecular detection of extended-spectrum $\beta$-lactamase producing Escherichia coli isolates from raw meat in Greater Accra region, Ghana. BMC Microbiol., 20(1): 1-8.

34. Monteiro, T., Wysocka, M., Tellez, E., Monteiro, O., Spencer, L., Veiga, E. and Araujo, I.I. (2020) A five-year retrospective study shows increasing rates of antimicrobial drug resistance in Cabo Verde for both Staphylococcus aureus and Escherichia coli. J. Glob. Antimicrob. Resist., 22: 483-487.

35. Hozzari, A., Behzadi, P., Khiabani, P.K., Sholeh, M. and Sabokroo, N. (2020) Clinical cases, drug resistance, and virulence genes profiling in uropathogenic Escherichia coli. J. Appl. Genet., 61(2): 265-273.

36. Ezemokwe, G.C., Aguiyi, J.C. and Chollom, F.P. (2020) The antibacterial activity of aqueous and ethanolic leaf extracts of Balanites aegyptiaca (L.) Del plant on some selected clinical human pathogens. J. Adv. Microbiol., 20(10): 51-66.

37. Ibrahim, M.A. and Emlee, A.M. (2020) Anti-fungal study on aqueous and ethanolic leaves extracts of Piper sarmentosum. Matrix Sci. Pharm., 4(1): 13.

38. Noshad, M. (2020) Evaluation of the effect of aqueous and ethanolic extraction methods on extraction yield, phenolic compounds, and antioxidant and antimicrobial activity of Stachys schtschegleevii extract. Food Sci. Technol., 17(100): 117-125.

39. Gonfa, T., Teketle, S. and Kiros, T. (2020) Effect of extraction solvent on qualitative and quantitative analysis of major phyto-constituents and in-vitro antioxidant activity evaluation of Cadaba rotundifolia Forssk leaf extracts. Cogent Food Agric., 6(1): 1853867. 
40. Yin, I.X., Zhao, I.S., Mei, M.L., Lo, E.C.M., Tang, J., Li, Q. and Chu, C.H. (2020) Synthesis and characterization of fluoridated silver nanoparticles and their potential as a non-staining anti-caries agent. Int. J. Nanomed., 15: 3207-3215.

41. Araruna, F.B., de Oliveira, T.M., Quelemes, P.V., de Araújo Nobre, A.R., Plácido, A., Vasconcelos, A.G. and da Silva, D.A. (2020) Antibacterial application of natural and carboxymethylated cashew gum-based silver nanoparticles produced by microwave-assisted synthesis. Carbohydr. Polym., 241(1): 115260.

42. Paul, S.C., Bhowmik, S., Nath, M.R., Islam, M.S., Paul, S.K., Neazi, J. and Salam, M.A. (2020) Silver nanoparticles synthesis in a green approach: Size-dependent catalytic degradation of Cationic and anionic dyes. Orient. J. Chem., 36(3): 360301.

43. Kate, S., Sahasrabudhe, M. and Pethe, A. (2020) Biogenic silver nanoparticle synthesis, characterization and its antibacterial activity against leather deteriorates. Jordan J. Biol. Sci., 13(4): 493-498.

44. Jana, S., Jasmin, N., Sen, K.K. and Maiti, S. (2020) Alginate nanostructures: Pharmaceutical approaches. Encyclopedia Mar. Biotechnol., 2: 767-782.

45. Loo, Y.Y., Rukayadi, Y., Nor-Khaizura, M.A.R., Kuan, C.H., Chieng, B.W., Nishibuchi, M. and Radu, S. (2018) In vitro antimicrobial activity of green synthesized silver nanoparticles against selected gram-negative food-borne pathogens. Front. Microbiol., 9: 1555.

46. De Lacerda Coriolano, D., de Souza, J.B., Bueno, E.V., Cavalcanti, I.D.L. and Cavalcanti, I.M.F. (2020) Antibacterial and antibiofilm potential of silver nanoparticles against antibiotic-sensitive and multidrug-resistant Pseudomonas aeruginosa strains. Braz. J. Microbiol., 52(1): 267-278.

47. Juknius, T., Juknienè, I., Tamulevičius, T., Ružauskas, M.,
Pampariene, I., Oberauskas, V. and Tamulevičius, S. (2020) Preclinical study of a multi-layered antimicrobial patch based on thin nanocomposite amorphous diamond-like carbon films with embedded silver nanoparticles. Materials, 13(14): 3180.

48. Žlabur, J.Š., Žutić, I., Radman, S., Pleša, M., Brnčić, M., Barba, F.J. and Voća, S. (2020) Effect of different green extraction methods and solvents on bioactive components of chamomile (Matricaria chamomilla L.) flowers. Molecules, 25(4): 810.

49. Presentato, A., Piacenza, E., Scurria, A., Albanese, L., Zabini, F., Meneguzzo, F. and Ciriminna, R. (2020) A new water-soluble bactericidal agent for the treatment of infections caused by gram-positive and gram-negative bacterial strains. Antibiotics, 9(9): 586.

50. Acosta-Gutiérreza, S., Bodrenkoc, I. and Ceccarellia, M. (2020) Permeability through bacterial porins dictate whole-cell compound accumulation. ChemRxiv, Available from: https://chemrxiv.org/ndownloader/files/21777774. Retrieved on 17-05-2021.

51. Anuj, S.A., Gajera, H.P., Hirpara, D.G. and Golakiya, B.A. (2020) The impact of bacterial size on their survival in the presence of cationic particles of nano-silver. J. Trace Elem. Med. Biol., 18(61): 126517.

52. Valentin, E., Bottomley, A.L., Chilambi, G.S., Harry, E.J., Amal, R., Sotiriou, G.A. and Gunawan, C. (2020) Heritable nano-silver resistance in priority pathogen: A unique genetic adaptation and comparison with ionic silver and antibiotics. Nanoscale, 12(4): 2384-2392.

53. Ngongang, F.C., Fankam, A.G., Mbaveng, A.T., Wamba, B.E., Nayim, P., Beng, V.P. and Kuete, V. (2020) Methanol extracts from Manilkara zapota with moderate antibacterial activity displayed strong antibiotic-modulating effects against multidrug-resistant phenotypes. Pharmacology, 3(1): 37. 